\title{
INTIMIDAD Y LAS MÚLTIPLES MANIFESTACIONES DE LA VIOLENCIA DOMÉSTICA ENTRE MUJERES LESBIANAS
}

\section{PRIVACY AND MULTIPLE FORMS OF DOMESTIC VIOLENCE AMONG PUERTO RICAN LESBIAN WOMEN}

Recibido: 01 de Abril del 2011 | Aceptado: 15 de Julio del 2011

\author{
MABEL T. LOPEZ ORTIZ $;$ i DENISSE AYALA MORALES \\ (UNIVERSIDAD DE PUERTO RICO, Recinto de Río Piedras, Puerto Rico).
}

\begin{abstract}
RESUMEN
La violencia doméstica (VD) es uno de los problemas de salud pública en Puerto Rico por su alta incidencia. Si bien estudios realizados apuntan a que el problema de la VD puede estar presente en todo tipo de parejas, las estadísticas en el país excluyen datos sobre parejas del mismo sexo. Las razones para explicar el silencio sobre este tipo de violencia están íntimamente relacionadas a la homofobia, al sexismo y a la discriminación contra las personas LGBT. Por lo que, con el propósito de explorar las experiencias sobre violencia en un grupo de mujeres lesbianas en Puerto Rico, realizamos un estudio cualitativo entrevistando a siete mujeres, reclutadas por disponibilidad mediante la técnica de "bola de nieve". Se empleó una guía de preguntas estructuradas para explorar los significados de la experiencia de la VD en sus diferentes manifestaciones. Encontramos en los relatos la percepción de que la VD entre parejas del mismo sexo es una situación invisibilizada en Puerto Rico, que no es atendida en la política social, ni en servicios de apoyo gubernamentales. Ante la realidad de tener que enfrentar la violencia perpetrada por sus parejas en todas sus manifestaciones, las entrevistadas ofrecieron recomendaciones en tres áreas: legal, capacitación a personas en servicios y creación de programas que apoyen personas LGBT
\end{abstract}

PALABRAS CLAVE: Violencia entre parejas, violencia doméstica; mujeres lesbianas, política social.

\section{ABSTRACT}

Domestic violence (DV) is a public health problem in Puerto Rico for its high incidence. Although studies suggest DV may be present in all types of couples, national statistics exclude data about same-sex couples. The reasons for the silence on this type of violence are closely related to homophobia, sexism and discrimination against LGBT people. In order to explore the experiences of violence in a group of lesbian women in Puerto Rico, we conducted a qualitative study interviewing seven women who were recruited for availability using the "snowball" technique. A structured question guide was used to explore the meanings of the DV experience in its different manifestations. In their accounts, we found the perception that DV between same-sex couples is an invisible problem in Puerto Rico, a situation that is not attended by social policies or government support services. Since the reality of violence confronted by their partners in all its manifestations, the interviewees made recommendations in three areas: legal support, training people in service programs and the need to develop programs that support LGBT people.

KEY WORDS: Violence between couples, domestic violence, lesbians, social policy.

1. Mabel T. López Ortiz, Ph.D. Investigadora, Profesora del Departamento de Trabajo Social de la Universidad de Puerto Rico, Recinto Río Piedras. E-mail: mabel.lopez2@upr.edu

2. Denisse Ayala Morales. Asistente de Investigación. Estudiante de maestría de la Escuela Graduada de Trabajo Social de la Universidad de Puerto Rico.Email: denisseayala18@hotmail.com 
Violencia entre parejas: El Contexto

Vivimos en sociedades donde la violencia se ha convertido en costumbre $y$ cotidianidad. La misma es transmitida por vías diversas entre los cuales se encuentran los medios de comunicación, las redes cibernéticas, las instituciones sociales y las experiencias vividas como testigos $y$ víctimas de las nuevas formas de respuestas de interacción social. La sobreexposición a ambientes saturados de violencia ha favorecido que asumamos y aceptemos con naturalidad las conductas violentas, tanto aquellas de gran sutileza hasta las más evidentes e impactantes (Rodríguez-Madera \& Toro-Alfonso, 2004). En este trabajo se enfatiza la violencia en el ámbito doméstico, donde ésta adquiere matices variados y traumáticos. En contradicción al discurso de lo doméstico, como el lugar en el cual co-habitan personas unidas por lazos familiares $y / 0$ afectivos, es allí donde se reproducen conductas violentas que laceran a las personas involucradas en ellas: la violencia entre parejas (Bachman \& Saltzman, 1995; Dorta, 2010; Rodríguez-Madera, 2005).

La violencia doméstica o violencia entre parejas del mismo sexo como nos referimos en esta investigación, se ha convertido en uno de los mayores problemas de salud pública en nuestra sociedad por su alta incidencia (NCAVP, 2006; OMS, 2002). El nivel de violencia entre las parejas trasciende la clase social, el origen étnico, el nivel socio-económico, el nivel educativo o la orientación sexual (Gay Men's Domestic Violence Project, 2002). Los asuntos relacionados a metodología, definiciones y la resistencia a reportar los casos hacen difícil una determinación real de la prevalencia de estos incidentes. Frecuentemente se destacan en los medios de comunicación pero de formas disfrazadas, remitiendo al dominio de lo privado, la vida doméstica.
La violencia doméstica se caracteriza por ser un patrón de conductas abusivas dentro del contexto de relaciones de intimidad, que también incluye las citas románticas casuales como de forma consecuente describen varios autores (Hickson et al., 1994; Merrill, 1999; Scarce, 1997). Las conductas violentas surgen como consecuencia de la acción deliberada de una persona sobre otra con el objetivo de controlarla, coaccionarla, dominarla y/o aislarla (Farley, 1996; Gondolf, 1984; National Coalition of Anti-violence Programs [NCAVP], 2000; Schornstein, 1997). Por tal razón, entendemos que la violencia doméstica es un asunto de poder y control, en tanto la persona que tiene poder sobre la otra es quien utiliza tácticas extremas para hacer sentir, valer y mantener el mismo. Tales estrategias se manifiestan a través de acciones violentas a nivel físico, emocional, y sexual (Russo, 1999). Estas acciones violentas entre parejas se tipifican en las manifestaciones de violencia física, psicológica y sexual.

En los últimos años, la violencia doméstica ha sido un tema muy tratado debido a la cantidad de víctimas que ha dejado tras su paso (Koss, 1990; NCAVP, 1997, 2000; Straus \& Gelles, 1990). Al respecto, en Puerto Rico se recogen estadísticas que apuntan al aumento de reportes de incidentes publicados en los medios de comunicación, reflejando la misma tendencia que existe en Estados Unidos (Policía de Puerto Rico, 2009; 2011). Como contradicción la prensa escrita mantiene la información de la incidencia de casos, e indicaba que para el mes de febrero de 2011 ya se habían registrado seis muertes de mujeres en manos de sus parejas, pero los datos oficiales informados por la División de Estadísticas de la Policía de Puerto Rico recogen la prevalencia del problema y muertes relacionadas hasta el año 2009. Esta división se encuentra al día en la información ofrecida de la incidencia de delitos Tipo I en su página electrónica. En los informes de estos tipos de delitos no 
se especifican la cantidad de los incidentes de violencia doméstica y las muertes relacionadas a este problema por lo que quedan englobados los datos reales. Sumamos a este hecho el que las estadísticas presentadas solo incluyen los incidentes de violencia entre parejas heterosexuales, excluyendo parejas del mismo sexo.

Las implicaciones del problema de la violencia doméstica se presentan en múltiples dimensiones: personales, sociales, económicas y políticas (Bachman \& Saltzman, 1995; Greenfeld et al., 1998). Además, representa un problema de salud pública por los daños psicológicos y físicos producidos, entre los cuales destacamos la posibilidad de la infección con el VIH/SIDA y otras enfermedades transmisibles sexualmente, ya que la literatura señala la práctica de no informar a la pareja del riesgo de infección de enfermedades como un mecanismo o manifestación de violencia contra la pareja, (Vélez et al., 2000). Las dimensiones y matices que ha tomado este problema en Puerto Rico, desde el ámbito de pareja hasta el de la política pública requiere la discusión y la atención del mismo por el Estado tanto en la prevención como de la intervención. Finalmente el objetivo principal de nuestro estudio fue explorar las experiencias de violencia doméstica en un grupo de mujeres lesbianas en Puerto Rico, e identificar los obstáculos y facilitadores en sus procesos de ayuda y de apoyo como víctimas de este problema.

\section{Violencia entre parejas del mismo sexo}

Históricamente se ha abordado el tema de la violencia doméstica como si fuera un asunto exclusivamente de parejas heterosexuales, lo que ha tenido como consecuencia que se ignoren las manifestaciones de este tipo de violencia en parejas del mismo sexo (Hamberger, 1996). Desde el análisis de la violencia entre parejas, como una estrictamente relacionada al género 0 relaciones heterosexuales, se excluye y mantiene al margen la discusión del tema en las relaciones entre parejas del mismo sexo (parejas de hombres o de mujeres). No fue hasta hace poco tiempo que miembros de la comunidad lésbica, gay, bisexual y transexual (LGBT) incorporaron como parte de su agenda el estudio de la violencia doméstica en parejas del mismo sexo (NCAVP, 1997; Renzetti, 1997, 1998; Shernoff, 1995). Particularmente, Lobel (1986) e Island y Letellier (1991) fueron los primeros en identificar que cerca de medio millón de hombres gays en los Estados Unidos habían sido víctimas de violencia doméstica y un número similar fueron agresores. Otro estudio encontró que uno de cada cuatro hombres había tenido relaciones de parejas marcadas por la violencia (NCAVP, 2000). Este estimado es congruente con las estadísticas reveladas en parejas de mujeres lesbianas (De Vidas, 1999; Klinger \& Stein, 1996).

Por otra parte, varios autores citan la investigación de Kelly y Warshafsky (1987) como pionera en el estudio de la violencia entre parejas de participantes gays y lesbianas, donde identificaron que el $47 \%$ de los participantes en dicho estudio en Norteamérica, estaban 0 habían estado involucrados en relaciones violentas (Renzetti, 1997; Rodríguez-Madera \&ToroAlfonso, 2005). En otras investigaciones realizadas con poblaciones de mujeres lesbianas, hombre gays y hombres que tienen sexo con hombres en Norteamérica y Puerto Rico por Burke y Follingstad (1999), Nieves-Rosa, Carballo-Diéguez y Dolezal (2000), y Toro-Alfonso (1999a; 1999b), se encontró que entre un 7 y un $35 \%$ de los y las participantes habían sido víctimas de violencia física; cerca de la mitad habían sido víctimas de abuso emocional; y una cuarta parte había tenido sexo anal sin protección bajo alguna forma de coerción y violencia sexual.

En Puerto Rico son pocos los estudios realizados sobre el tema de la violencia 
entre parejas del mismo sexo, pero existen pioneros y pioneras que han aportado al inicio de la discusión sobre el mismo (Franco, Malavé \& Toro-Alfonso, 2005; Toro-Alfonso, 1999a, 1999b; Toro-Alfonso \& Rodríguez-Madera, 2005). Toro-Alfonso y Rodríguez-Madera (2005) identificaron la prevalencia de la violencia doméstica en parejas del mismo sexo en Puerto Rico. Establecieron que cerca del $60 \%$ de las personas participantes en su estudio reportaron al menos un incidente de violencia emocional, física y/o sexual en sus relaciones. Franco et al. (2005) describieron la prevalencia de la violencia doméstica en lesbianas puertorriqueñas y exploraron las necesidades de atención y servicios disponibles en Puerto Rico para lesbianas víctimas de la violencia de pareja. Estos autores encontraron que a pesar de la existencia del problema de violencia entre parejas de mujeres no existen servicios adecuados que atiendan las necesidades de estas.

Sobre la dimensión del género presente en la violencia entre parejas del mismo sexo Reyes, Rodríguez y Malavé (2005) encontraron diferencias en las manifestaciones del tipo de violencia de acuerdo al género del o la victimaria. Entre éstas el maltrato físico y psicológico fue recibido mayormente en el grupo de las mujeres lesbianas que participaron del estudio, pero el abuso sexual fue estadísticamente mayor experimentado por el grupo de los hombres homosexuales.

Entendemos que las razones para explicar por qué la violencia entre parejas del mismo sexo fue un problema silenciado por tanto tiempo están íntimamente relacionadas a la práctica de la homofobia, el sexismo y la discriminación en contra de las personas LGBT. Además, varios autores y autoras aseguran que también existía temor por parte de los/as miembros de la comunidad gay y lésbica a que el reconocimiento público de esta problemática implicara un aumento en los ataques homofóbicos provenientes de la comunidad heterosexual y sectores conservadores (Elliott, 1996; Hamberger, 1996; Island \& Letellier, 1991; Merrill, 1999; Renzetti, 1992).

El primer paso para el estudio y la reflexión de este fenómeno social es reconocer que el problema de la violencia doméstica puede estar presente en todas las parejas sin importar la orientación sexual de las personas. Si bien múltiples teóricos (Burke \& Follingstad, 1999; Elliott, 1996; Farley, 1996; Hamberger, 1996; Island \& Lettelier, 1991; Merrill, 1999) han ofrecido explicaciones para entender este fenómeno social, es importante destacar que no existe una razón exclusiva que nos ayude a comprender por qué la violencia doméstica se suscita. De allí que los acercamientos a ésta deban partir de una perspectiva multidimensional que tome en consideración aspectos individuales y sociales de las personas involucradas. Entre estas dimensiones, destacamos las siguientes: (1) la influencia que ejerce en la persona abusiva la exposición al modelaje de roles en el contexto del hogar y el aprendizaje vicario, (2) el ambiente social violento que fomenta que la persona agresora sea abusiva, y (3) que la persona agresora carezca de destrezas de manejo de conflicto, lo que propicia que entre toda la gama de alternativas que existe para solucionar una situación, elija ser violenta (Toro-Alfonso \& Rodríguez-Madera, 2005).

Sobre la violencia doméstica entre parejas de mujeres, pudimos identificar que los estudios apuntan en dirección de registrar la incidencia de situaciones y las causales tradicionales desde la mirada del género entre otras perspectivas (Burke \& Follingstad, 1999; Kaschack, 2001; Renzetti, 1997; 1998). A pesar de la escasa literatura publicada, la misma ofrece una idea sobre la prevalencia de la violencia doméstica en parejas del mismo sexo. En Puerto Rico, partiendo de un enfoque cuantitativo, Franco et al. (2005) estudiaron las 
necesidades de las mujeres lesbianas víctimas de violencia doméstica y la falta de servicios que atiendan este fenómeno. Informaron que ellas no identifican este problema en sus relaciones pero en contradictoria informan haber enfrentado algunas de sus manifestaciones física, emocional o verbal con sus parejas. Según los autores posiblemente relacionado a la característica del género y a su socialización y cultura dominantemente homofóbica.

A partir del análisis de la bibliografía citada con relación a metodología predominantemente cuantitativa, entendimos que podían quedar escondidos los significados, las historias y las implicaciones que tienen la experiencia de violencia entre parejas del mismo sexo en la vida particular de cada víctima, así como la descripción de sus procesos en la búsqueda de ayuda o apoyo y la disponibilidad de servicios para atender su problema. Por esta razón, el presente estudio se dirigió a explorar este fenómeno desde el enfoque cualitativo para conocer y examinar de cerca las experiencias subjetivas desde la mirada individual de las mujeres involucradas, víctimas de violencia por parte de la pareja del mismo sexo. Entendemos que las consecuencias del problema de violencia entre parejas atentan contra la dignidad y la salud del ser humano, por lo que amerita el estudio y la reflexión sobre historias reales de mujeres lesbianas que enfrentan tanto la realidad de recibir maltrato de su pareja en todas las manifestaciones como el laberíntico proceso de buscar ayuda para enfrentarlo.

\section{Violencia entre parejas del mismo sexo y su relación con la opresión institucionalizada}

Las situaciones que podemos identificar entre los relatos cotidianos de parejas del mismo sexo que enfrentan el fenómeno de la violencia doméstica y la falta de extensa investigación sobre el mismo, nos llevó a explorar la disposición actual de servicios, programas y leyes que atienden esta problemática. En Puerto Rico no existe reconocimiento legal de las parejas del mismo sexo y protección para las víctimas de violencia. Al respecto, la Ley 54 del año 1989 define relación de pareja como: "relación entre cónyuges, ex cónyuges, las personas que cohabitan o han cohabitado, las que sostienen 0 han sostenido una relación consensual íntima y los que han procreado entre sí un hijo o una hija." Esta definición parece dejar a la interpretación jurídica la aplicabilidad a las parejas del mismo sexo, que luego quedan excluidas en otras instancias del documento de ley y del Código Civil, por referirse en específico a parejas heterosexuales. La discusión pública sobre la protección de las personas LGBT se ha encaminado en dirección a la legalidad del matrimonio, la posibilidad de adopción de estas parejas, entre otras, obviando situaciones que requieren de atención y apoyo institucional 0 de las instancias gubernamentales, como lo es la violencia doméstica.

Cuando nos referimos al concepto de opresión institucional señalamos las acciones 0 falta de acciones de las instituciones sociales con poder político, económico, social y cultural, que excluyen a un sector de la sociedad del acceso a la calidad de vida que requerimos fundamentadas en valores, creencias y prejuicios (Marsiglia \& Kulis, 2009). Un ejemplo de esta opresión y de la resistencia de la política pública del país a reconocer parejas que no son heterosexuales, se ha demostrado en el rechazo férreo a incluirlas como parejas de hecho, en las enmiendas del Código Civil en el año 2003. En este aspecto la exclusión de las parejas LGBT demuestra una acción legal que obstaculiza la atención de este fenómeno por parte de las instancias gubernamentales. En su estudio sobre el derecho a la ciudadanía de las personas LGBT, Toro-Alfonso (2007) encontró que el gobierno y sus instituciones se muestran débiles en la atención y el compromiso con esta población. 
La falta de reconocimiento desde la condición ciudadana, así como el mito de que no existe este problema en parejas del mismo sexo, nos deja frente a una situación invisibilizada que parecería no requerir de atención por parte de la política social y los servicios de apoyo del gobierno. El refrán popular "ojos que no ven, corazón que no siente" podría dar cuenta de la descripción del contexto de la violencia entre mujeres lesbianas. Se adiciona a la invisibilidad y negación del Estado, la propia comunidad LGBT, mostrando resistencia a reconocer y sumar otro estigma que se revierte como discriminación social contra ésta.

Con este panorama político-social y con un análisis desde la perspectiva del género, puede construirse un imaginario de que es imposible la existencia del problema de la violencia entre dos mujeres que son pareja. La construcción de un ideal de la feminidad que caracteriza a la mujer como un ser débil, sumiso, víctima de agresión por parte de los hombres, resta a la credibilidad de este problema entre dos mujeres. Es importante que podamos comprender el problema de la violencia doméstica o la violencia entre parejas como uno motivado por la intención de controlar y mantener el poder de una de las partes de la pareja sobre la otra. De esta manera es posible reconocer que la violencia doméstica no discrimina entre tipos de parejas, y así poder manejar y atender la misma, tanto desde el Estado, la comunidad LGBT, como por la sociedad en general. Sin embargo, los patrones de comportamiento abusivo observados en las relaciones del mismo género, muy a menudo presentan la misma dinámica de los presentes en las relaciones heterosexuales abusivas. Además, de reconocer que de igual forma que existen controles sexistas creados y perpetuados en una cultura patriarcal, hay una multitud de maneras que nuestra sociedad y la comunidad LGBT otorga derechos y control a algunas personas o grupos sobre la justificación de otras características de la identidad. La raza, capacidad mental y física, estado migratorio, edad, clase social, entre otros, son algunas formas de privilegio que se utilizan a menudo como un medio para oprimir y mantener el control en una relación abusiva (NCAVP, 2006)

\section{METODOLOGÍA}

El objetivo del presente estudio de corte cualitativo fue explorar las experiencias de violencia doméstica en un grupo de mujeres lesbianas en Puerto Rico, e identificar obstáculos y facilitadores en el proceso de ayuda y de apoyo como víctimas de este problema. Las participantes de la investigación fueron siete mujeres, reclutadas por disponibilidad utilizando la técnica de "bola de nieve". El rango de edad de las mujeres participantes fue de 22 a 58 años. Con respecto a su orientación sexual, seis se reconocieron como lesbianas y una de ellas como bisexual. Todas afirmaron ser puertorriqueñas, con preparación académica de grado superior, bachillerato 0 maestría. Por último, una de ellas se encontraba desempleada y seis trabajando a tiempo parcial y completo.

Las entrevistas fueron realizadas siguiendo una guía de preguntas estructuradas para explorar los significados que las participantes le atribuían a las experiencias de violencia doméstica, así como las diferentes manifestaciones de este fenómeno (física, emocional y sexual), y a sus procesos de ayuda, como sus percepciones sobre servicios disponibles y la política pública en el país (Apéndice A).

Todas las entrevistas fueron de forma individual en la oficina de la investigadora. Las mismas fueron audio-grabadas y transcritas en su totalidad para posterior análisis de contenido, con la rigurosidad y confidencialidad de la ética en la investigación con personas. Se utilizó una lista de categorías previamente diseñadas por la investigadora y otras que surgieron desde las descripciones de las participantes para el manejo del contenido de las 
entrevistas. Antes de comenzar las participantes debieron leer, discutir y firmar un consentimiento informado, guardando así la protección y el respeto a la participación voluntaria e informada. Este protocolo de investigación fue aprobado por el Comité Institucional para la Protección de Sujetos en la Investigación (CIPSHI) de la Universidad de Puerto Rico Recinto de Río Piedras (\# 0809-110).

\section{HALLAZGOS Y DISCUSIÓN}

\section{Experiencias con la Violencia Doméstica en el hogar de origen}

Presenciar violencia en las familias en la niñez se ha discutido como uno de los contextos que puede provocar conductas violentas futuras en las relaciones de parejas. Como parte de la guía de entrevista se exploró con estas mujeres si habían presenciado experiencias de violencia en su hogar de origen, encontrando que seis de ellas sufrieron dichas situaciones. Estas mujeres relataron historias de violencia en sus hogares de origen que generaron en ellas sentimientos diversos como miedo, inseguridad, coraje y frustración. Específicamente, la violencia se generó entre sus padres y madres, muchas de estas situaciones con el agravante del uso de alcohol por parte del victimario, el padre. Los siguientes apartados de contenido respaldan estos postulados:

"Salía de la oficina [refiriéndose al padre] y pues se cambiaba... y llegaba tomado a la casa, a romper. Siempre era por celos. Siempre tenía una persecución encima." (\#1)

"En ocasiones que tuvimos que dejar la casa [madre y hermanos]... nosotros salir corriendo, mi mamá con nosotros, por esa situación de violencia, o sea de golpes; mi papá también se daba la bebida y mayormente eso pasaba [el evento de violencia] cuando mi papá se daba la bebida y llegaba borracho, y pues le daba con mi mamá." (\#2)
"Mi papá tiene problemas de alcohol y cuando bebe se pone violento, se pone celoso, controlador y mi madre es una persona sumisa, [de] temperamento pasivo. $Y$ pues, en diferentes ocasiones eso ha traído problemas, aparte de que cuando yo era más pequeña él era bien enamorado..., y eso traía violencia." (\#5)

Seis de las mujeres describieron el recuerdo de cómo se sentían cuando presenciaron estos eventos de violencia en sus hogares, como citamos a continuación.

\begin{abstract}
"Se me adormecían las piernas, para mí era el estado más horrible que me ofrecía el mundo, como uno es un niño y uno siente deseos de no sentirlo más... de no sentirlo más. $Y$ cuando pasaba cualquier cosa, enseguida empezaba a sentir como un adormecimiento, calambre, calentón, un montón de cosas a la vez." (\#1)

"Porque yo sí me ponía sumamente nerviosa... y cualquiera entra en un estado de pánico, te diría yo... uno está pendiente a su mamá o que hace, y uno siempre como que confía que la persona que lo guarda a uno, ¿verdad? ... te va a buscar una alternativa de protección, pero eso pues pasó...," (\#2)
\end{abstract}

"Pues impotente porque no podía hacer nada, ya yo desde pequeña sabía que cuando los niños dicen, no quiero que mis papás se divorcien...yo no los entiendo, porque yo sí sabía que eso era lo que debía pasar [el divorcio] porque entre ellos no podía haber una relación, me sentía que no podía hacer nada. " (\#5)

"Horrible, se siente feo tu saber que tus papás están peleando y que puede pasar algo." (\#6)

Para explorar las múltiples manifestaciones de la violencia entre parejas enfrentadas por las mujeres entrevistadas en sus relaciones, se utilizó una guía sobre conductas de violencia física, emocional y sexual. Encontramos que todas las entrevistadas recibieron violencia física como alones de 
pelo, bofetadas, patadas, puños, cortaduras, entre otras, que en algunos de los casos las llevaron a solicitar y recibir atención médica y policíaca. Todas aseguraron haber respondido a la violencia física con agresiones físicas, pero en menor frecuencia y con el fin de defenderse. Por otro lado, entre los relatos se describieron algunas de estas situaciones de agresión como eventos significativos que en ocasiones representaron el momento de la decisión de terminar la relación.

"Fue lo último. Ya vivíamos juntas pero como que tú por tú lado y yo por el mío. Fue en la discoteca. Me tiró con una botella de medalla [cerveza local] y me rajó la ceja, Me cocieron cuatro puntos... ella estaba conociendo a otra persona, $y$ supuestamente por celos fue que ella me dio con la botella; dije ya 'la próxima vez me va a matar', y ahí empezamos a cortar la relación. Estuvo presa, y yo fui y la saqué. " (\#7)

Exploramos el uso de alcohol y drogas durante los eventos violentos entre estas mujeres y sus parejas y encontramos que dos de las entrevistadas aseguraron que sus parejas y ellas estaban bajo el uso de alcohol durante eventos de violencia física, una de las entrevistadas tenía la percepción que su pareja utilizaba alguna droga pero no lo afirmó como un hecho corroborado. Reyes, et al., 2005 encontraron en sus hallazgos que el uso de alcohol y drogas en incidentes violentos era mayor en frecuencia en mujeres lesbianas que en la muestra de hombres gays.

"Bebíamos mucho alcohol, lo cual yo no bebía así tanto [antes de comenzar la relación con esta pareja]...Empiezo a aceptar la violencia de su parte hacia mi... violencia física pero la toleraba, pues no sé porqué, estaba deslumbrada... (\#5)."

Todas estas mujeres identificaron ser víctimas de las manifestaciones psicológicas de la violencia. En algunos de los relatos de las participantes pudimos identificar como mecanismo de control en este tipo de violencia, el aislamiento de las víctimas de sus sistemas o redes de apoyo. Estos datos concurren con otros autores revisados en estudios con mujeres lesbianas donde informan que éstas enfrentan y son victimas mayormente de la violencia emocional o psicológica (Franco, et al., 2005; Reyes et al., 2005)..

\begin{abstract}
"Muchas lastimaduras hacia la autoestima de uno,... hay muchas formas de hacerte sentir que tú no eres importante o que tú no sabes... muchas, muchas maneras y eso... yo lo viví, yo lo vivía. Muchas maneras de hacerte ver que 'lo que necesito de ti es que me resuelvas esto', sin decirtelo." (\#1)
\end{abstract}

"Ella me hizo sentir como siempre se ha estudiado, que yo fui la culpable de 10 que pasó y todo. O sea, la manipulación de ella era toda psicológica a nivel de que yo me sentía,...yo básicamente no tenía autoestima,... ella me decía que yo no tenía amistades, 'tú no tienes amistades mija [mi hija], tú no sabes mantener una amistad, tú no sabes'. Como que yo no sabía hacer amistades ni mantener una amistad..., de que yo no sabía valerme por mi misma, de que todo lo que yo había logrado o tenía era por ella, [aunque] hacia solamente dos años que yo la conocía; 'tú no eres nadie sin mi' o sea, ella era el cerebro de nosotras dos, yo no tenía cerebro básicamente. Usaba mucho para humillarme [la profesión de la entrevistada], '[nombre de la profesión] de mierda'... cosas asi bien humillante y 'eso lo estudia cualquiera eso cualquiera lo hace' " (\#3).

Las entrevistadas indicaron no haber experimentado manifestaciones de violencia sexual en sus relaciones de pareja, esto es diferente a las investigaciones revisadas. En estudios cuantitativos realizados en los Estados Unidos se encontró que la violencia sexual es muy común como manifestación de violencia entre parejas de mujeres lesbianas (Renzetti, 1992). 
Encontramos un relato donde la mujer entrevistada describió un incidente mientras tenía relaciones sexuales con su pareja que incluimos a continuación que puede ser interpretado como violencia sexual,

"Eh... le explico [a la pareja] eso me duele, hazlo más suave, [le contestó] 'no importa yo lo quiero hacer asi', y entonces en el mismo acto [sexual], tener que aguantarle los brazos, las manos y decirle pero por favor, te lo estoy pidiendo por favor... [tener que] cambiar el acto [sexual] por algo de suplica, cuando se supone que aquí disfrutemos ambas." (\#1)

Las historias descritas por estas siete mujeres sobre sus experiencias de violencia de parte de sus parejas, ilustran similitudes entre ellas. Incluimos a continuación relatos de todos los tipos de manifestaciones de violencia por parte de sus parejas enfrentados por las entrevistadas con el propósito de conocer las realidades descritas como víctimas y sus respuestas 0 reacciones en algunos de estos incidentes.

"Yo me levanto y abro [un portón], y le digo que pasó, '¿tu estas ahí con fulana?', entonces me menciona a una [persona]..., y yo digo, 'aquí yo no estoy con nadie', entonces ahí mismo, en ese mismo movimiento abro el portón... voy entrando a la sala, ahí mismo cuando se abre el screen que yo la miro, ahí mismo [en ese momento] me mete la bofetada." (\#1)

"En el proceso de realizar que ella estaba mal... el momento de la violencia fue cuando yo la dejé, aparentemente... no quería estar más con ella, el problema es que aunque yo le dije eso, luego hago un intento de volver con ella o de estar con ella otra vez,... ese intento fue altamente peligroso, ahí por poco yo pierdo la vida. Pero entonces en esa ocasión que la dejé, [ella] fue a mi oficina [y] se alteró, cogió todo lo que había ahí [en el escritorio], ahí encima me lo tiró, encima [del escritorio]... [ella] empezó a gritar 'eso no es posible tu no me puedes dejar, que no es posible'... pues es mi decisión [le dije] tu sabes tienes que bregar con eso... [entre los objetos] las cosas [con] que me agredió cogió... una grapadora y me la tiró... a la cara,... yo hice asi [gesto de evadir el golpe] pa' [para] que no me diera me cogió aquí... [en el rostro]"(\#2)

"Me tomó mucho tiempo superar... esa relación desde los seis meses que comenzó, comenzó el maltrato emocional, psicológico... esa persona comenzó como yo digo, por estudiar cómo era yo, que cosas me gustaban, etc., etc., y esos primeros seis meses fueron eso [estudiarla], preguntar, buscarme la vuelta, ver que a mí me gustaba, conocerme... uno analizando todo después que todo pasa y pasó. [Estudiar] como poderme controlar, y como poderme manipular emocionalmente... luego que ella me conoce... ya a los seis meses... nosotras vivíamos en una casa que... era propiedad mía, ella empieza a insistirme, 'vamos a mudarnos a un sitio que sea de las dos'... porque ella se sentía que yo tenía el control por el hecho de que era mi casa...yo creo que eso también influenció mucho... inmediatamente que nos mudamos entonces ahi ella me dijo textualmente 'ahora yo voy hacer todo 10 que dejé de hacer estos seis [meses]."(\#3)

\section{Servicios y personal de apoyo}

Este grupo de mujeres dilató su proceso de buscar y solicitar ayuda, aislándose y sufriendo la violencia en silencio. Por temor al rechazo luego de revelar su orientación sexual, mayormente optaban por compartir sus situaciones con amistades y no con la familia. Por otra línea, Renzetti y Harvey (1996) aseguran que la falta de apoyo 0 programas de servicio para las victimas de violencia entre parejas del mismo sexo media en la decisión de terminar una relación violenta.

"Yo tenía una amiga, que de hecho, eso era terrible, porque ella me prohibió terminantemente hablar con esa 
persona... yo la llamaba... pero a escondidas de ella, que ella no se enterara que yo había hablado con ella." (\#3)

"... unos celos que no me dejaba ni siquiera yo hacer casting [para modelaje] ni hacer nada, era una cosa horrible, no me dejaba... o sea si hablaba con el fotógrafo, si hablaba con alguien, lo que fuera, todo era un rollo [problema]... [Eran] los celos y de la única manera que pude irme [y] dejar a esa persona fue conociendo unos muchachos que eran gay. Lo que yo hice fue sacar mi ropa poco a poco, iba sacando mi ropa a la casa de ese muchacho hasta que tomé la decisión [de terminar la relación]." (\#4)

Cuando las entrevistadas solicitaron ayuda de algún servicio gubernamental fue de la policía, destacando relatos de poco conocimiento e insensibilidad del personal policíaco y del sistema de justicia.

"... solicité [ayuda] obviamente con la policía, consulté en el trabajo, pero no se toman en serio [el problema] así con mujeres, no se toman en cuenta, en cuanto cuán grave es la situación... yo le notifiqué a la policía en la primera situación [de violencia con una pareja anterior] y en esta última relación habian muchísimos informes a la policía, pero lo mismo, [los argumentos del personal policiaco] no pero si ella es dueña de esto[ un negocio compartido], ella tiene derecho de meterse ahí, y pues golpearme, lo que fuera." (\#4)

"Ujum [afirmando], se la llevaron ahí mismo, en la disco se la llevaron y estuvo dos días [en prisión] creo yo... obviamente pagamos [la víctima y otras amigas] la fianza y pues salió; después, yo tumbé el caso [proceso judicial]...En la corte el juez dice [se ríe], esto es violencia doméstica porque ella se viste de nene y parece un nene, y la abogada le dice no, es una nena, y él se quedó como, [asombrado] ah,... ok, pero nada, ...estuvo dos minutos ahí en silencio y después como que cayó en cuenta, ah... ok, fue una pelea, entonces fue que lo describió como una pelea." (\#7)

Todas describen haber buscado y recibido ayuda psicológica del sector privado de forma individual 0 en pareja. En este proceso de mejorar la relación de pareja, atesorando el deseo de cambio de conducta de la victimaria, continuaban en sus relaciones, a pesar de la consecuencia negativa sobre la salud emocional de algunas, también luego de terminada la relación. Los relatos de este grupo de mujeres lesbianas poseen contingencias con la discusión y descripción en la literatura sobre las consecuencias, las expectativas y el deseo de cambio de sus parejas 0 victimarios de las parejas heterosexuales. De forma similar, queda plasmado a través de estas historias el efecto devastador de la violencia sufrida en la salud integral de estas mujeres, reiterando la interpretación de la violencia entre parejas como una que requiere atención desde la perspectiva de la salud pública. Los siguientes relatos describen algunos de los procesos en la solicitud de ayuda y servicios psicológicos de las mujeres entrevistadas.

"Entramos en terapia y todo eso [refiriéndose a la ayuda psicológica]; primero ella no quería porque decía que como yo estudiaba [profesión de ayuda en el campo de la salud mental] yo conocía a todos [los y las profesionales de ayuda] y que podía manipular la información y a la gente, entonces ahí yo le dije llámala tu [refiriéndose a la ayuda] búscala tu, y has tú la gestión y así fue." (\#3)

"En un momento dado solicité ayuda psicológica; fuimos a un psiquiatra pero no fue para eso [problema de violencia entre pareja], ahí fue que me di cuenta de que las cosas que me habían pasado [eran manifestaciones de violencia entre parejas]..." (\#4) 
"Yo fui a una psicóloga pero fui sola no fui con ella, fue una psicóloga... fue una sesión nada más." (\#5)

"...luego de terminar la relación como que seguía con lo mismo [pensando en la ex pareja], y me acordaba de las cosas y me deprimía, pues iba una psicóloga... (\#7)."

"Constantemente yo quería [buscar ayuda], pero ella tenía, ejercía una manipulación muy grande sobre mi... la etapa esa de reconciliación cada vez era más breve y cada vez el lapso de tiempo que pasaba entre reconciliación y volver a la pelea era más corto... cada vez." (\#5)

A pesar del deseo de cambio de sus parejas violentas, este grupo de mujeres buscó ayuda para terminar la relación, luego de algún evento de violencia física donde sintieron que corría peligro su integridad física.

"...fue lo último[último evento de violencia física], ya vivíamos juntas pero como que tu por tu lao... y yo por el mío; fue en la discoteca me tiró con una botella de medalla y me rajó la ceja, me cogieron cuatro puntos [en la ceja]... por celos [de la pareja], ya ella estaba conociendo otra persona, y [a pesar de esto] supuestamente por celos fue que ella me dio con la botella; dije ya la próxima vez me va a matar y ahí empezamos a cortar la relación, estuvo presa y yo fui y la saqué, fui yo quien la saqué, le dije pues está bien pero ya." (\#7)

Desde la experiencia de sus procesos de esa búsqueda de apoyo, exploramos qué opinaban las mujeres entrevistadas de las personas que se encuentran ofreciendo servicios a las parejas víctimas de violencia doméstica. Sobre el particular, todas las mujeres coincidieron en que: 1) las personas que ofrecen servicios a víctimas de violencia doméstica son homofóbicas, 2) por lo que entienden que requieren de adiestramientos sobre temas relacionados a las personas LGBT, 3) aunque la mayoría opina que las personas en estos programas, no poseen el interés de adiestrarse sobre la violencia entre parejas del mismo sexo, y que no desean trabajar con este tipo de parejas por homofobia. Incluimos sus relatos con relación a su opinión de ofrecer adiestramiento a estos funcionarios $y$ funcionarias.

"... [El personal que ofrece servicios necesita] el tener más tolerancia, tener más apertura, tener más aceptación, ... hacía falta eso mismo... el adiestrar al personal para que pudieran trabajar en las circunstancias específicas de la comunidad [LGBT] etc., etc., así que pues basándome en la experiencia que tuve... creo que pudiese ser positivo [ofrecer adiestramiento a ese personal]." (\#3)

"Tratar a todos por igual, porque siempre pasa que nos [a las personas LGBT] marginan, marginan por sexo, por el trato sexual; A los homofóbicos [personal que ofrecen servicios] me imagino... los homofóbicos, los cristianos, estos que dicen que los homosexuales no van al cielo, y que son cosas de otro planeta." (\#6)

"Yo pienso que están prejuiciados [personal que ofrece servicios] o que desconocen... lamentablemente a veces somos invisibles, somos invisibles [personas LGBT] ante la gente heterosexual." (\#4)

"No creo que tengan el interés, no porque desde mi vivencia propia [experiencia], la comunidad gay es bien estigmatizada, las personas automáticamente tienen todo un prejuicio montao [construido] y nos ven como otra cosa, y que no ellos, no le ven la pertinencia de poder ayudarnos, la solución estaría, en pues no ser homosexual o lesbiana y ya estamos resueltos el problema." (\#5)

Específicamente para atender los obstáculos que han enfrentado estas mujeres entrevistadas con el personal que 
ofrece servicios a las víctimas de violencia doméstica -programas que se dirigen a parejas heterosexuales- ofrecieron sugerencias sobre los temas que deben incluirse en el adiestramiento de este personal si ofrecieran servicios a las víctimas de violencia entre parejas LGBT:

* Estilo de Vida de las personas gays y lesbianas

* Violencia entre parejas del mismo sexo: consecuencias, causales, entre otras

* Relaciones entre parejas del mismo sexo

* Herramientas de apoyo legal

El último tema sugerido por las participantes se refería específicamente a la condición de exclusión social en la que se encuentran las personas LGBT en Puerto Rico, y el paralelismo, en lo que este grupo de mujeres opina sobre las políticas sociales creadas para atender el problema de la violencia doméstica. Para ellas es necesario que se comience a incluir en la Ley 54 de 1989 de Violencia Doméstica, a todo tipo de parejas, sin importar su orientación sexual. La aplicabilidad de esta Ley a parejas del mismo sexo, ayudaría a las personas LGBT, las cuales, desde la opinión de las entrevistadas, están desprovistas de protección en la actualidad.

"... [Necesitamos] en verdad apoyo, eso es lo más primordial, apoyo, porque es que no lo tenemos, o sea, solamente la comunidad gay se apoya entre sí, más nada, asi es. Hay una población grande [de personas LGBT], pero como quiera, debemos tener la ayuda de alguien más, de los que tienen el poder, porque si no tenemos el poder ¿qué vamos hacer?, $\mathrm{Nada}$, simplemente manifestarnos y ya, y se queda ahí, es como todo lo demás... como la religión. Mira yo sé que eso es importante [refiriéndose a las prácticas religiosas], pero hay cosas más importantes porque... ¿tú vas a dejar que maten a alguien? No eso fue una pelea, no hay violencia doméstica... y eso no es justo para nosotros [personas LGBT]." (\#7)

"Nosotros [personas LGBT] no vivimos
en una tribu, nosotros tenemos que
aportar económicamente a la sociedad
en que vivimos y recíprocamente esa
sociedad tiene que tener esos servicios
disponibles hacia nosotros que somos
contribuyentes también. O sea, vivimos
en una sociedad material totalmente y
esto se trata de un canjeo siempre,
siempre. Y es porque tenemos que
olvidarnos que si nació con dos penes, o
una vulva y un pene, y respiro y tiene
alma... es lo único que importa." (\#1)

Algunos de estos relatos permean una opinión sin expectativas de cambios reales que ofrezcan los derechos y condiciones equitativas que todas las personas esperan en una sociedad democrática, la desesperanza que fue descrita en algunos de los relatos de las entrevistadas. Como muestra un estudio realizado en Puerto Rico sobre la ciudadanía de las personas LGBT, éstas poseen una percepción de exclusión social y discriminación que pueden correlacionarse con los altos niveles de prejuicios que muestran las personas que laboran en programas de servicio gubernamentales (Toro-Alfonso, 2007). Como efecto de la homofobia y opresión internalizada, las personas muestran sentimientos de impotencia, desesperanza a cambios sociales que las beneficien $y$ tensiones de vivir o ser parte de un grupo minoritario (Balsam, 2001; Barreto \& Quiñones, 2000; Marsiglia \& Kulis, 2009).

\section{Recomendaciones de las entrevistadas sobre política social}

Como resultado de las entrevistas, este grupo de mujeres desde su experiencia e historia expresaron varias recomendaciones que interpretan como posibles soluciones al problema de la violencia doméstica entre parejas de mujeres lesbianas. Discutiremos las recomendaciones de este grupo con relación a tres áreas: apoyo legal, adiestramientos a personas en programas 
de servicios y la necesidad de crear programas que apoyen a las personas LGBT. Para atender este problema en la primera área o dimensión las entrevistas señalan que las parejas del mismo sexo deben incluirse en la protección legal sobre prevención y manejo de violencia doméstica. Tal como se indicó en los apartados anteriores, Puerto Rico carece de leyes que protejan a las personas LGBT que enfrentan este problema. Existe una falta de reconocimiento a las parejas no heterosexuales que implica exclusión y marginación social en la política pública del gobierno. A pesar de que el Estado reconoce que el problema de la violencia doméstica es un problema de salud pública en Puerto Rico, esta interpretación deja al margen y no incluye otro tipo de parejas.

Ante la realidad de tener que enfrentar la violencia perpetrada por sus parejas en todas sus manifestaciones, y los obstáculos presentados al solicitar apoyo, las entrevistadas ofrecieron recomendaciones para abordar esta problemática a nivel gubernamental. Entre sus recomendaciones centralizan en el ofrecimiento de adiestramientos para las personas que están en servicios de apoyo. Para las entrevistadas estas personas deben obtener conocimientos sobre varios temas para estar preparadas para atender la población LGBT. Específicamente no solo conocer sobre la problemática de la violencia entre parejas si no también comprender, ser sensibles y poseer competencias sobre el trabajo con personas LGBT.

La ley y la política pública del Estado deben dirigirse a la creación de programas y servicios para atender las necesidades del pueblo civil, esta situación no parece ser así según la percepción de las entrevistadas. Pudimos compartir con estas mujeres su opinión sobre las consecuencias de la falta de reconocimiento por parte del Estado. Estas entienden que la misma genera la inexistencia de programas de servicio y apoyo para ellas como mujeres lesbianas víctimas de violencia por sus parejas en la política social. En este camino concordaban en que existe la necesidad de crear programas de servicios para ofrecer apoyo a las personas LGBT, que enfrentan este problema.

Esta realidad descrita e interpretada por este grupo de entrevistadas puede ser considerada como el primer paso en reconocer la existencia de la violencia entre parejas del mismo sexo, en este estudio, de mujeres lesbianas.

\section{REFLEXIONES FINALES}

El problema de la violencia entre parejas de mujeres lesbianas parece existir en todas las manifestaciones: física, psicológica y sexual (Franco et al., 2005; Reyes et al., 2005; Toro-Alfonso \& Rodríguez-Madera, 2005). Aunque nos enfrentemos a la falta de reconocimiento político y social, que resulta en los matices que afectan la salud de las personas LGBT, este estudio nos ofreció historias que reiteran lo que resume la literatura sobre el paralelo entre las parejas LGBT y las heterosexuales (Balsam, 2001; Elliott, 1996; Franco et al., 2005; . Las diferencias se estilan en la falta de leyes, de servicios y de apoyo que encuentran tanto mujeres como hombres homosexuales, que atentan con la posible terminación de una relación de violencia con la pareja. Es interesante como algunas de ellas identifican la homofobia relacionada a prácticas o ideologías religiosas, cómo la raíz de la falta de interés tanto del Estado como de las personas en general. Varios estudios realizados en Puerto Rico muestran esta realidad, señalan que los niveles más altos de homofobia poseen una correlación con las prácticas y creencias religiosas en las personas (Nieves, 2008; Toro-Alfonso \& Varas-Díaz, 2004). Una alternativa que sugerimos para trabajar con el problema de violencia relacionado a la exclusión social o las manifestaciones de opresión sobre las personas LGBT, es la educación desde inicios escolares sobre el 
reconocimiento y manejo de la diversidad desde una perspectiva de derechos humanos. Como Franco et al. (2005) recomiendan la prevención de la violencia doméstica de forma masiva dirigida a todas las poblaciones en Puerto Rico, con énfasis en los y las niñas.

Para las mujeres entrevistadas, la situación con la política social en Puerto Rico la cual deja descubierta a las parejas LGBT que enfrentan el problema de la violencia, figura como prioridad y urgencia que debe ser atendida por el Estado, con lo que concurrimos. Por otro lado, la sensación de desesperanza entre este grupo de entrevistadas se puede identificar ante la percepción de que el gobierno y sus proveedores de servicio no tienen interés por crear políticas inclusivas para ofrecer servicios a esta población. A pesar de identificarse como personas que aportan al país, se perciben como ciudadanas de segunda categoría a las que el gobierno no les interesa proteger, lo cual parece ser una percepción del concepto de opresión internalizada (Toro-Alfonso, 2007). La opresión internalizada surge frente a un escenario donde las ideas cargadas de prejuicios y estereotipos que mantienen la opresión institucionalizada, impactan la dimensión individual, llevando a las personas a creer que los mensajes negativos 0 incorrectos creados por sectores dominantes son ciertos (Balsam, 2001; Barreto \& Quiñones, 2000). Precisamente, una de las consecuencias de este fenómeno social es el sentimiento de desesperanza hacia el cambio que percibimos en estas historias. Una línea de investigación que invitamos a las personas lectoras de este artículo a explorar e incluir en la discusión de la violencia entre parejas de mujeres lesbianas es la condición de la doble discriminación, ser mujer y lesbiana, que no se examinó, ni surgió entre los hallazgos de este estudio, pero que queda para futuros trabajos.
Este estudio nos dio la oportunidad de conocer en profundidad los relatos e historias de personas que han sufrido casi en silencio la cruda realidad del ejercicio violento del poder y el control en su relación de pareja. Estas realidades no se distancian de las descritas por mujeres heterosexuales en la literatura, pero descansan en el olvido por estar al margen de un mundo heterosexista. Entendemos que el valor de estos relatos reitera tanto la existencia de la violencia doméstica entre mujeres lesbianas como la necesidad de prevención, atención e intervención de este problema en Puerto Rico.

Falta crear conciencia y fomentar la educación sobre los derechos humanos y civiles que poseemos todas las personas, sin distinción de credo, género, raza u orientación sexual, así como llamar la atención sobre los efectos de una realidad de violencia entre parejas invisibilizadas en Puerto Rico. Entendemos que la falta de servicios $y$ leyes que prevengan e intervengan con el problema de la violencia entre parejas del mismo sexo es una manifestación de opresión sobre las personas LGBT, así que el compromiso debe ser develar estas realidades descritas por las mujeres entrevistadas para enfrentar, combatir y transformar la política social existente en Puerto Rico. Este es el reto que las historias compartidas nos develan a la crítica de la exclusión y distancia en las que hemos posicionado a un sector de nuestra sociedad basándonos en mitos y prejuicios construidos y heredados por la historia. El reto está en crear programas inclusivos de prevención e intervención del problema de la violencia doméstica y desde la política social del país. 


\section{REFERENCIAS}

Bachman, R. \& Saltzman, L. (agosto, 1995). Violence against women: Estimates from a redesigned survey, Bureau of Justice Statistics, Special Report. Washington, D.C.: US Department of Justice.

Balsam, K. (2001). Nowhere to hide: Lesbian battering, homophobia, and minority stress. En E. Kaschak (Ed.) (2001). Intimate Betrayal: Domestic violence in lesbian relationships New York: The Haworth Press.

Barreto, E. \& Quiñones, R. (2000). Un modelo de bienestar y desarrollo integral y sus

implicaciones para la práctica del profesional de ayuda. Revista Análisis, 2(1), 1- 28.

Burke, L. \& Follingstad, D. R. (1999). Violence in lesbian and gay relationships: Theory, prevalence, and correlational factors. Clinical Psychology Review, 19, 487-512.

De Vidas, M. (1999). Childhood sexual abuse and domestic violence: A support group for Latino gay men and lesbians. Journal of Gay \& Lesbian Social Services, 10, 51-68.

Dorta, J. (2010). La violencia neoliberal: Un análisis macroestructural del "sicario de hoy". Para Servirte, XII, 13-16; Publicación Oficial del Colegio de Trabajadores Sociales de Puerto Rico.

Elliott, P. (1996). Shattering illusions: Same sex domestic violence. En C. M. Renzetti \& C. $\mathrm{H}$. Miley (Eds.), Violence in gay and lesbian domestic relationships (pp. 1-8). New York, NY: Harrington Park Press.

Farley, N. (1996). Same sex domestic violence. En E. Dworkin \& F. J. Gutierrez (Eds.), Gay men and lesbians: Journey to the end of the rainbow. (pp. 231-242). Alexandria, VA: American Association for Counseling Development.

Franco, S., Malavé, S., \& Toro-Alfonso, J. (2005). La violencia doméstica y las necesidades de servicios relacionados de una muestra de mujeres lesbianas en Puerto Rico. En J. Toro-Alfonso \& S. Rodríguez-Madera (Eds.), Al margen del género: La violencia doméstica en parejas del mismo sexo (pp. 73-96). San Juan, PR: Ediciones Huracán.

Gay Men's Domestic Violence Project. (2002). Myths and facts about same-gender domestic violence. Recuperado en, http://www.gmdvp.org/pages/myth.html
Gondolf, E. (1984). Men who batter: An integrated approach for stopping wife abuse. Holmes Beach, Fl: Learning Publications.

Greenfeld, L., Rand, M., Craven, D., Klaus, P., Perkins, C., \& Ringel, C. (marzo, 1998). Violence by intimates (NCJ No. 167237). Washington, D.C.: US Department of Justice.

Hamberger, L. K. (1996). Intervention in gay male intimate violence requires coordinated efforts on multiple levels. En C. M. Renzetti \& C. H. Miley (Eds.), Violence in gay and lesbian domestic relationships (pp. 83-91). New York, NY: Harrington Park Press.

Hickson, F., Davies, P., Hunt, A., Weatherburn, P., McManus, T., \& Coxon, A. (1994). Gay men as victims of non-consensual sex. Archives of Sexual Behavior, 23, 281-294.

Island, D., \& Lettelier, P. (1991). Men who beat the men who love them: Battered gay men and domestic violence. New York: Harrington Park Press.

Kaschack, E. (Ed.). (2001). Intimate Betrayal: Domestic Violence in Lesbian Relationships. New York: The Haworth Press.

Klinger, R., \& Stein, T. (1996). Impact of violence, childhood sexual abuse, and domestic violence and abuse on Lesbian, Bisexual, and Gay men. En R. Cabaj \& T. Stein (Eds.), Textbook of homosexuality and mental health (pp. 801-818). Washington, DC: American Psychiatric Press.

Koss, M. P. (1990). The women's mental health research agenda: Violence against women. American Psychologist, 45, 375-380.

Ley \# 54 del 15 de agosto de 1989, Ley para la prevención e intervención de la violencia doméstica. San Juan, Puerto Rico.

Lobel, K. (Ed.). (1986). Naming the violence: Speaking out about lesbian battering. Seattle, WA: Seal Press.

Marsiglia, F. \& Kulis, S. (2009). Diversity, oppression, and change. Chicago: Lyceum Books.

Merrill, G. (1999). 1 in 3 of 1 in 10: Sexual and dating violence prevention groups for lesbian, gay, bisexual, and transgendered youth. En B. Levanthal \& S. Lundy (Eds.), Same-sex domestic violence: Strategies for change (pp. 201-213). Thousand Oaks, CA: Sage. 
National Coalition of Anti-violence Programs (1997). Annual report on lesbians, gay, transgender domestic violence. Washington, DC: Autor.

National Coalition of Anti-violence Programs (2000). Lesbian, gay, transgender and bisexual (LGBT) domestic violence in 1999. New York, NY: Autor.

National Coalition of Anti-violence Programs (2006). Lesbian, gay, transgender and bisexual (LGTB) domestic violence in 1999. New York, NY: Autor.

Nieves, L. (2008, Enero-Marzo). Homofobia, opresión y ciudadanía: Retos del Trabajo

Social en el Siglo XXI. Para Servirte, IX, 1011; Publicación Oficial del Colegio de Trabajadores Sociales de Puerto Rico.

Nieves-Rosa, L., Carballo-Dieguez, A., \& Dolezal, C. (2000). Domestic Abuse and HIV-risk behavior in Latin American men who have sex with men in New York City. Journal of Gay \& Lesbian Social Services, 11, 77-90.

Organización Mundial de la Salud. (2002). Informe Mundial sobre la Violencia y la Salud. OMS: Autor. Recuperado en http://www.who.int/violence_injury_preventi on/violence/world_report/en/summary_es.p $\mathrm{df}$

Policía de Puerto Rico (2009). Incidentes de Violencia Doméstica por Área. Gobierno de Puerto Rico: autor. Recuperado en http://www.gobierno.pr/PoliciaPR/Estadistic as/

Policía de Puerto Rico (2011). Relación de Delitos Tipo I. Gobierno de Puerto Rico: autor. Recuperado en http://www.gobierno.pr/PoliciaPR/Estadistic as/

Renzetti, C. (1992). Violent betrayal partner abuse in lesbian relationships. CA: SAGE Publications.

Renzetti, C. \& Harvey, C. (Eds.) (1996). Violence in Gay and Lesbian Domestic Patnerships. New York: Harrington Park Press.

Renzetti, C. (1997). Violence and abuse among same-sex couples. En A. P. Caldarelli (Ed.), Violence between intimate partners: Patterns, causes, and effects (pp. 70-89). Needham Heights, MA: Allyn \& Bacon.

Renzetti, C. (1998). Violence and abuse in lesbian relationships: Theoretical and empirical issues. En R. Kennedy-Bergen (Ed.), Issues in intimate violence (pp. 117-
128). Thousand Oaks, CA: Sage Publications.

Reyes, F., Rodríguez, J. R., \& Malavé, S. (2005). Manifestaciones de la violencia doméstica en una muestra de hombres homosexuales y mujeres lesbianas puertorriqueñas. Revista Interamericana de Psicología, 39, 449-456.

Russo, A. (1999). Lesbian organizing lesbians against battering. En B. Levanthal \& S. Lundy (Eds.), Same-sex domestic violence: Strategies for change (pp. 83-96). Thousand Oaks, CA: Sage.

Rodríguez-Madera, S. (2005). Trascendiendo la marca del género: Reflexiones sobre las violencias domésticas como prácticas sociales y retos para la acción. En J. ToroAlfonso \& S. Rodríguez-Madera (Eds.), Al margen del género: La violencia doméstica en parejas del mismo sexo (pp. 125-136). San Juan, PR: Ediciones Huracán.

Rodríguez-Madera, S., \& Toro-Alfonso, J. (2005). Description of a domestic violence measure for Puerto Rican gay males. Journal of Homosexuality, 50, 155173.

Rodríguez-Madera, S., \& Toro-Alfonso, J. (2004). Como en tu casa: El legado de la violencia intergeneracional en las relaciones de pareja en un grupo de hombres gay puertorriqueños. En $\mathrm{L}$. Oblitas (Ed.), Manual de psicología de la salud. México, DF: Thompson Iberoamerica

Scarce, M. (1997). Male on male rape: The hidden toll of stigma and shame. New York: Plenum Press.

Schornstein, S. L. (1997). Domestic violence and health care: What every professional needs to know. Thousand Oaks, CA: Sage Publications.

Shernoff, M. (1995). Gay men: Direct practice. En R.L. Edwards (Ed.), Encyclopedia of Social Work $19^{\text {th }}$ Edition (pp. 1075-1085). Washington, D.C.: National Association of Social Workers.

Straus, M. A., \& Gelles, R. J. (1990). How violent are American families? Estimates from the National Family Survey and other studies. En M. A. Straus \& R. J. Gelles (Eds.), Physical violence in 8,145 American families (pp. 95-132). New Brunswick, NJ: Transaction.

Toro-Alfonso, J. (1999a). Domestic violence among same-sex partners in the gay, 
lesbian, bisexual, and transgender communities in Puerto Rico: Approaching the issue. En B. Leventhal, \& S. Lundy (Eds.), Same-sex domestic violence (pp. 157-164). Thousand Oaks, CA: Sage.

Toro-Alfonso, J. (1999b). Hidden in the closet: Same sex domestic violence, Implications for intervention. Journal of Gay \& Lesbian Social Services. 9, 69-79.

Toro-Alfonso, J. (2007). Por la vía de la Exclusión: Homofobia y ciudadanía en Puerto Rico. Comisión de Derechos Civiles: Estado Libre Asociado De Puerto Rico.

Toro-Alfonso, J., \& Rodríguez-Madera, S. (Eds.) (2005). Al margen del género: La violencia doméstica en parejas del mismo sexo. San Juan, P. R.: Ediciones Huracán

Toro-Alfonso, J. \& Varas-Díaz, N. (2004). Los otros: Prejuicio y distancia social hacia homosexuales y lesbianas en una muestra de estudiantes de nivel universitario. Revista Internacional de Psicología Clínica y de la Salud, 4, 3, pp 537-551.

Vélez, C., Vega, J., Torres, D., Martínez, Z., Sánchez, M., Fumero, A. Ríos, E., Cardona, S., González, L., Umpierre, A. Godreau, A. (2000). La violencia doméstica: Un reto para la investigación en salud pública. Mujer \& Salud, 4, 12-19. 
APÉNDICE A:

GUÍA DE PREGUNTAS

\author{
Universidad de Puerto Rico \\ Facultad de Ciencias Sociales \\ Departamento de Trabajo Social
}

La intimidad de las múltiples manifestaciones de la violencia: La violencia doméstica en parejas de lesbianas en Puerto Rico

\title{
Código \#
}

CIPSHI \# 0809-110

\section{Entrevista estructurada}

Toro-Alfonso, J. \& López Ortiz, M., 2008

Entrevistador/a: Gracias por aceptar participar de esta entrevista. La información que usted provea será de gran utilidad para entender las situaciones de violencia doméstica en parejas del mismo sexo. Por favor conteste todas las preguntas los más sinceramente posible y siéntase en la libertad de preguntarme cualquier duda o pregunta que no entienda. Recuerde que puede decidir no contestar alguna pregunta que le incomode o detener la entrevista en el momento que así usted lo decida.

Antes de continuar, debemos completar el proceso de consentimiento informado. Como parte del mismo, le hago entrega de una hoja donde le informamos sobre los pormenores del estudio y los riesgos potenciales del mismo. Si usted estuviese de acuerdo con estos detalles puede autorizar con su firma, iniciales o una $X$ su participación en el estudio o de no estar de acuerdo sólo tiene que dejar la hoja sin firmar. Recuerde que el no participar "no le afectará en ninguna medida." Entrevistador/a: Favor de proveerle un tiempo a la participante para que lea la hoja de consentimiento informado y la firme.

Parte 1.a: Cernimiento Inicial:

1. ¿Cuántas relaciones de compromiso con mujeres ha tenido usted en toda su vida?

(SI NINGUNA, ESCRIBA "0" Y DETENGASE AQUÍ. SI 10 MÁS, CONTINUE) [Si contesta ninguna, darles las gracias y dar por terminada la entrevista]

Número de parejas de compromiso

2. ¿Alguna vez has recibido abuso emocional o físico por parte de su pareja o de alguien importante para ti?

[1] Sí [0] No

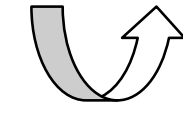

Si contesta NO, darle las gracias e indicarle que no cualifica para la investigación. Termina la entrevista.

Parte 1.b: Características Socio-demográficas 
A continuación le haré una serie de preguntas generales sobre su persona. Le agradeceremos que conteste cada una de las preguntas lo más sinceramente posible.

1. Edad:

2. ¿A qué género pertenece o con cuál se identifica usted?

$$
\text { Femenino }
$$

Transgénero/Transexual

Otro: especifique:

3. ¿Cuál de las siguientes describe mejor su origen nacional?
Puertorriqueña
Dominicana
Estadounidense
Cubana
Otro: especifique

4 ¿Cuál fue el último grado escolar que completó?

Primero a octavo grado (1-8)

Parte de escuela superior ( 9 a menos de 12)

Terminó escuela superior (o aprobó el examen de equivalencia)

Educación técnica-vocacional, algo de educación universitaria o grado asociado

Bachillerato

Algo de Escuela Graduada

Escuela Graduada (maestría, doctorado)

5 ¿Cuál de las siguientes alternativas describe mejor su orientación sexual?

Lesbiana
Homosexual
Heterosexual
Bisexual
Otro especifique

6. ¿Cuál aseveración describe mejor su situación actual? Puede marcar más de una alternativa.

Estudio a tiempo completo

__ Estudio a tiempo parcial

Estoy desempleada actualmente

Tengo un empleo a tiempo parcial

Tengo un empleo a tiempo completo

Otro: especifique:

7. ¿Cuál de las siguientes alternativas describe mejor su ingreso anual?
(1) $\quad 0-4,999$
_(2) $5,000-9,999$
- (3) $10,000-19,999$
- (4) $20,000-29,999$
- (5) $30,000-39,999$
- (6) $40,000-49,999$
- (7) $50,000-59,999$
- (8) $60,000-69,999$
_ (9) $\quad 70,000 \rightarrow$ o más 
Parte 2: Experiencias con la violencia doméstica en el hogar de origen

NOTA: Para comprender mejor los conceptos que hablaremos creo que sería importante definir lo que entendemos por violencia doméstica: definimos "violencia física" - como cualquier contacto físico o acción no deseada, que podría poner en peligro la salud de una persona o causarle un daño serio a su cuerpo. Definimos la "violencia emocional o psicológica"- como la conducta expresada para crear temor, intimidación, aislamiento que pueda causarle daño psicológico a una persona. Finalmente, la "violencia sexual" la definimos como cualquier contacto sexual forzado o sin consentimiento de una de las personas involucradas.

8. Me gustaría que me hablara sobre su familia de origen; su padre, madre y hermanos/as. Cuénteme sobre las experiencias con la violencia doméstica - si alguna - en su familia de origen.

- Por favor, abunde sobre los actos de violencia entre tus padres (si aplica).

- Describa cómo se sentía cuando presenciaba o escuchaba actos violentos en su hogar entre sus padres (si aplica).

- Por favor abunde sobre las experiencias de violencia entre usted y sus hermanos(as) o entre sus hermanos(as), (si aplica).

Parte 3: Conductas de violencia en las relaciones:

Muchas parejas experimentan diferentes tipos de problemas en sus relaciones. Las preguntas que le haré a continuación exploran la frecuencia de las situaciones. Para el resto de las preguntas "su(s) pareja(s)" se refiere solamente a aquellas mujeres con los que ha tenido relaciones de compromiso.

Entrevistador(a): Favor de indicar con una marca de cotejo $(\checkmark)$ si la persona entrevistada o su(s) pareja(s) han realizado alguna de las siguientes conductas que se mencionan a continuación.

\begin{tabular}{|l|l|l|l|l|l|}
\hline \multicolumn{2}{|c|}{ Conductas } & Nunca & $\begin{array}{c}\text { Rara } \\
\text { Vez }\end{array}$ & $\begin{array}{c}\text { Algunas } \\
\text { Veces }\end{array}$ & $\begin{array}{c}\text { Frecuente- } \\
\text { mente }\end{array}$ \\
\hline \multirow{2}{*}{$\begin{array}{l}\text { 9. Negarse a hablarle para } \\
\text { controlar o castigar. }\end{array}$} & a. Su pareja & & & & \\
\hline & b. Usted & & & & \\
\hline $\begin{array}{l}\text { 10. Negar cariño o sexo para } \\
\text { controlar o castigar. }\end{array}$ & a. Su pareja & & & & \\
\hline & b. Usted & & & & \\
\hline \multirow{2}{*}{$\begin{array}{l}\text { 11.Usar insultos o comentarios } \\
\text { degradantes. }\end{array}$} & a. Su pareja & & & & \\
\hline & b. Usted & & & & \\
\hline $\begin{array}{l}\text { 12. Expresar celos } \\
\text { intensos/exagerados. }\end{array}$ & a. Su pareja & & & & \\
\hline & b. Usted & & & & \\
\hline
\end{tabular}




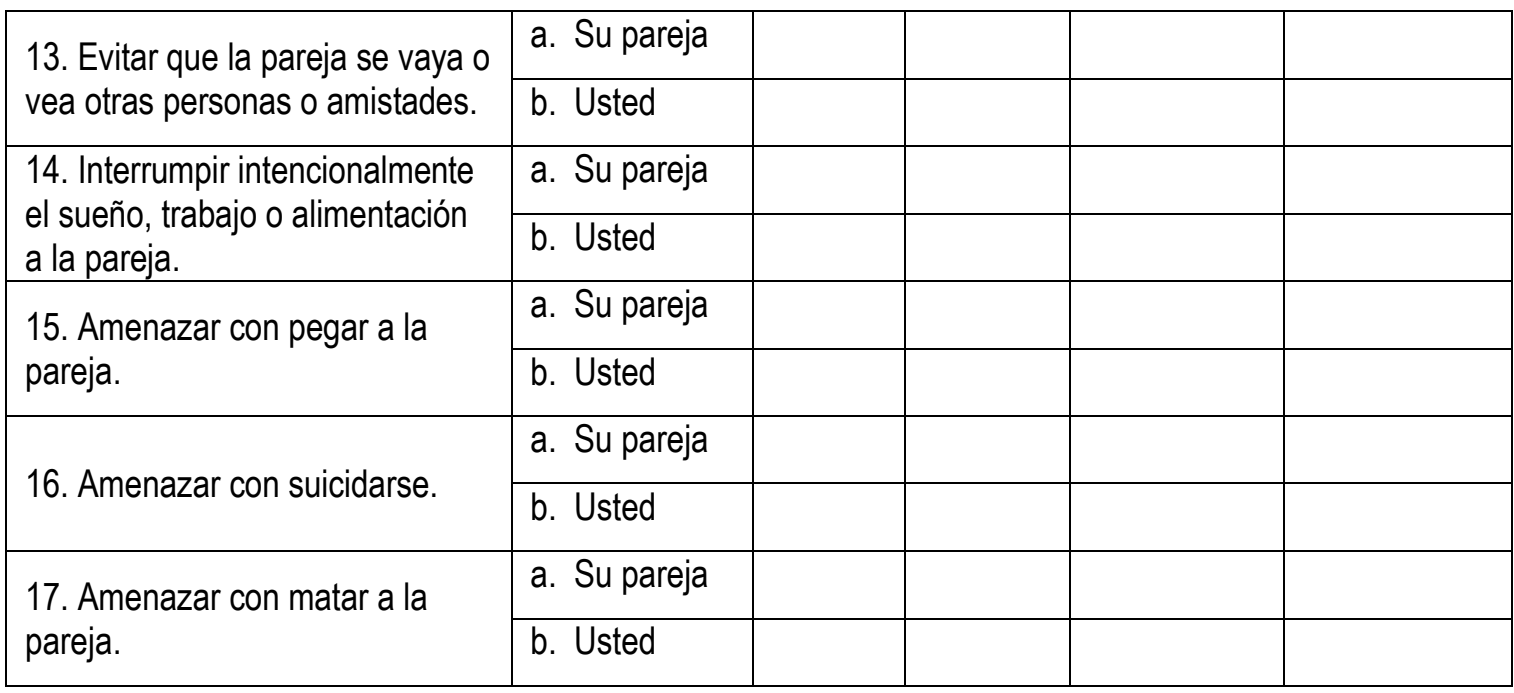

18. ¿Algunas de las conductas mencionadas anteriormente suceden en su relación actual?

$\begin{array}{ll}(0) & \text { NO } \\ (1) & \text { SI }\end{array}$

\begin{tabular}{|l|l|l|l|l|}
\hline $\begin{array}{l}\text { ¿Sucedió algunas de las conductas mencionadas } \\
\text { anteriormente mientras... }\end{array}$ & Nunca & $\begin{array}{c}\text { Rara } \\
\text { Vez }\end{array}$ & $\begin{array}{c}\text { Algunas } \\
\text { Veces }\end{array}$ & $\begin{array}{c}\text { Frecuente- } \\
\text { mente }\end{array}$ \\
\hline $\begin{array}{l}\text { 19- ...estaba/n su/s pareja/s bajo la influencia del } \\
\text { alcohol o drogas? }\end{array}$ & & & & \\
\hline $\begin{array}{l}20-\ldots \text { estaba usted bajo la influencia de alcohol o } \\
\text { drogas? }\end{array}$ & & & & \\
\hline
\end{tabular}

Indique si usted o su/s pareja/s han realizado algunas de las siguientes conductas:

\begin{tabular}{|c|c|c|c|c|c|}
\hline \multicolumn{2}{|l|}{ Conductas } & Nunca & $\begin{array}{l}\text { Rara } \\
\text { Vez }\end{array}$ & $\begin{array}{l}\text { Algunas } \\
\text { Veces }\end{array}$ & $\begin{array}{l}\text { Frecuente- } \\
\text { mente }\end{array}$ \\
\hline \multirow{2}{*}{$\begin{array}{l}\text { 21. Arrojar o tirar cosas a la } \\
\text { pareja. }\end{array}$} & a. Su pareja & & & & \\
\hline & b. Usted & & & & \\
\hline \multirow{2}{*}{ 22. Empujar a la pareja. } & a. Su pareja & & & & \\
\hline & b. Usted & & & & \\
\hline \multirow{2}{*}{ 23. Amarrar a la pareja. } & a. Su pareja & & & & \\
\hline & b. Usted & & & & \\
\hline \multirow{2}{*}{$\begin{array}{l}\text { 24. Pelear/luchar violentamente con } \\
\text { la pareja. }\end{array}$} & a. Su pareja & & & & \\
\hline & b. Usted & & & & \\
\hline \multirow{2}{*}{ 25. Abofetear/golpear a la pareja. } & a. Su pareja & & & & \\
\hline & b. Usted & & & & \\
\hline \multirow{2}{*}{$\begin{array}{l}\text { 26. Intentar estrangular a la } \\
\text { pareja. }\end{array}$} & a. Su pareja & & & & \\
\hline & b. Usted & & & & \\
\hline
\end{tabular}




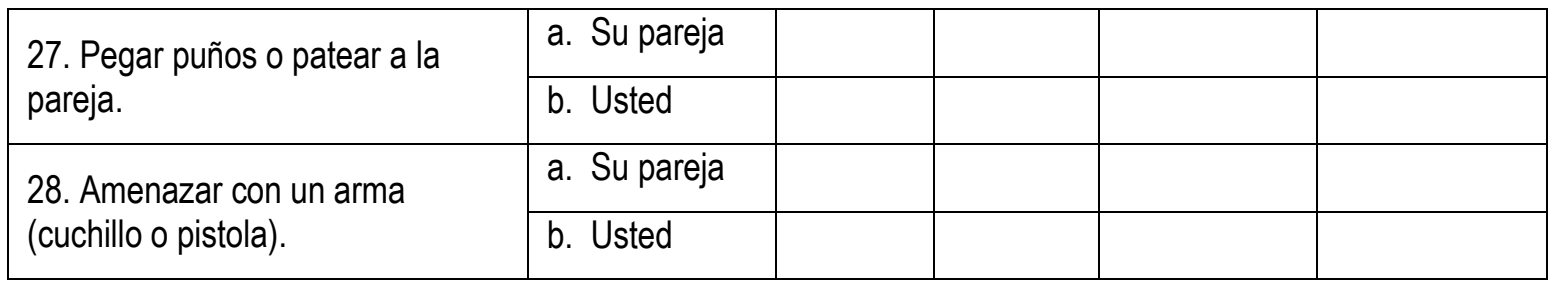

29. ¿Alguna de las conductas mencionadas anteriormente sucede en su relación actual?

(0) NO

(1) SI

\begin{tabular}{|c|c|c|c|c|}
\hline $\begin{array}{c}\text { ¿Alguna de las conductas mencionadas } \\
\text { anteriormente sucedió mientras... }\end{array}$ & Nunca & $\begin{array}{l}\text { Rara } \\
\text { Vez }\end{array}$ & $\begin{array}{c}\text { Algunas } \\
\text { Veces }\end{array}$ & $\begin{array}{l}\text { Frecuente- } \\
\text { mente }\end{array}$ \\
\hline $\begin{array}{l}30-\text {...estaba/n su/s pareja/s bajo la influencia del } \\
\text { alcohol o drogas? }\end{array}$ & & & & \\
\hline $\begin{array}{l}31-\text {...estaba usted bajo la influencia de alcohol o } \\
\text { drogas? }\end{array}$ & & & & \\
\hline
\end{tabular}

\begin{tabular}{|c|c|c|c|c|}
\hline Con cualquiera de sus parejas, alguna vez usted... & Nunca & Rara vez & $\begin{array}{l}\text { Algunas } \\
\text { veces }\end{array}$ & $\begin{array}{l}\text { Frecuente- } \\
\text { mente }\end{array}$ \\
\hline $\begin{array}{l}\text { 32. ... ¿fue penetrada vaginalmente por que ella le } \\
\text { amenazó con terminar la relación si usted no accedia? }\end{array}$ & & & & \\
\hline $\begin{array}{l}\text { 33. ... ¿fue penetrada analmente por que ella le amenazó } \\
\text { con terminar la relación si usted no accedía? }\end{array}$ & & & & \\
\hline $\begin{array}{l}34 . . . \text { ¿fue penetrada con un objeto por que se sentía } \\
\text { presionada por su insistencia? }\end{array}$ & & & & \\
\hline 35. ... ¿le mintieron para penetrarla con un objeto? & & & & \\
\hline 36. ... ¿la forzaron físicamente a besarla? & & & & \\
\hline 37. ... ¿la forzaron físicamente a acariciarla? & & & & \\
\hline 38. .. ¿la forzaron físicamente a hacerle sexo oral? & & & & \\
\hline $\begin{array}{l}\text { 39. ... ¿la forzaron físicamente a masturbarse } \\
\text { mutuamente? }\end{array}$ & & & & \\
\hline $\begin{array}{l}40 . . . . i \text { la forzaron físicamente para tener sexo vaginal } \\
\text { con un objeto? }\end{array}$ & & & & \\
\hline $\begin{array}{l}41 . . . \text { i la forzaron físicamente para tener sexo anal con } \\
\text { un objeto? }\end{array}$ & & & & \\
\hline $\begin{array}{l}\text { 42. ... ¿ la penetraron vaginalmente con un objeto por que } \\
\text { la amenazaron físicamente de no hacerlo? }\end{array}$ & & & & \\
\hline $\begin{array}{l}\text { 43. ... i la penetraron analmente con un objeto por que la } \\
\text { amenazaron físicamente de no hacerlo? }\end{array}$ & & & & \\
\hline
\end{tabular}




\begin{tabular}{|c|c|c|c|c|}
\hline Con cualquiera de sus parejas, alguna vez usted... & Nunca & Rara vez & $\begin{array}{l}\text { Algunas } \\
\text { veces }\end{array}$ & $\begin{array}{l}\text { Frecuente- } \\
\text { mente }\end{array}$ \\
\hline $\begin{array}{l}\text { 44....ंla penetraron con un objeto por que sintió la } \\
\text { necesidad de complacerla? }\end{array}$ & & & & \\
\hline $\begin{array}{l}\text { 45. ...¿Amenazó con terminar su relación a menos que } \\
\text { su pareja le dejara penetrarla con un objeto? }\end{array}$ & & & & \\
\hline $\begin{array}{l}\text { 46. ... ¿Presionó para penetrar con un objeto, aún } \\
\text { cuando su pareja no quería? }\end{array}$ & & & & \\
\hline $\begin{array}{l}\text { 47. ...¿Mintió para penetrar a su compañera con un } \\
\text { objeto? }\end{array}$ & & & & \\
\hline $\begin{array}{l}\text { 48. ...¿ ¿Usó algún grado de fuerza física para hacer que } \\
\text { su compañera le besara? }\end{array}$ & & & & \\
\hline $\begin{array}{l}\text { 49. ...¿¿Usó algún grado de fuerza física para hacer que } \\
\text { su compañera le acariciara? }\end{array}$ & & & & \\
\hline $\begin{array}{l}\text { 50. ...¿ ¿ Usó algún grado de fuerza física para hacer que } \\
\text { su compañera y usted se masturbaran mutuamente? }\end{array}$ & & & & \\
\hline $\begin{array}{l}51 . . . \text { ¿Usó algún grado de fuerza física para hacer que } \\
\text { su compañera tuviese sexo oral con usted? }\end{array}$ & & & & \\
\hline $\begin{array}{l}\text { 52. ...¿ ¿Usó fuerza física para penetrar a su compañera } \\
\text { con un objeto? }\end{array}$ & & & & \\
\hline $\begin{array}{l}\text { 53. ...¿Penetró con un objeto a su compañera } \\
\text { amenazándola con usar fuerza física si ella no accedía? }\end{array}$ & & & & \\
\hline
\end{tabular}

54. ¿Alguna de las conductas mencionadas anteriormente sucede en su relación actual?

(0) NO

(1) SI

\begin{tabular}{|l|l|l|l|l|}
\hline Pregunta: & Nunca & $\begin{array}{c}\text { Rara } \\
\text { Vez }\end{array}$ & $\begin{array}{c}\text { Algunas } \\
\text { Veces }\end{array}$ & $\begin{array}{c}\text { Frecuente- } \\
\text { mente }\end{array}$ \\
\hline $\begin{array}{l}\text { 55. ¿Estaba/n su/s pareja/s bajo la influencia del } \\
\text { alcohol o drogas cuando ocurrió alguno de estos } \\
\text { eventos? }\end{array}$ & & & & \\
\hline $\begin{array}{l}\text { 56. ¿Estaba usted bajo la influencia de alcohol o } \\
\text { drogas cuando ocurrió alguno de estos eventos? }\end{array}$ & & & & \\
\hline
\end{tabular}

Parte 4: Narración de eventos importantes

57. Por favor cuéntenos alguna experiencia de violencia en cualquiera de sus manifestaciones que haya tenido con alguna de sus parejas.

58. Al momento de estos eventos usted terminó la relación, continúo, pensó que la persona cambiaría.... Por favor abunde sobre esto. 
Parte 5: Búsqueda de ayuda o sistemas de apoyo

59. ¿Usted considera que ha sido víctima de violencia doméstica en alguna de sus relaciones? Abunde sobre esto.

60. ¿Alguna vez solicitó ayuda para tratar de manejar la violencia en sus relaciones? (si aplica)

Hábleme sobre estas ocasiones. A quien solicitó ayuda. Por que sí o porque no, solicita ayuda.

61. ¿Usted considera que en alguna de sus relaciones su(s) compañeras(s) han sido víctima(s) de violencia doméstica? Podría abundar sobre esto.

62. Cuénteme sobre la reacción de sus amigos y amigas frente a estos eventos. Cuánto sabían, qué le decían, contaba usted con esas personas para ayudarle en caso de emergencia...

63. ¿Explíqueme a donde usted recurriría para pedir ayuda en caso de ser nuevamente víctima de violencia doméstica?

\section{Parte 6: Política Pública}

64. ¿Qué piensa sobre la política pública en Puerto Rico con relación a la Ley 54 y su aplicabilidad a parejas del mismo sexo?

65. ¿Qué piensa de que las organizaciones que ofrecen servicios a víctimas de violencia doméstica ofrezcan servicios a personas gays o lesbianas?

66. ¿Cree usted que las organizaciones que ofrecen servicios a mujeres víctimas de violencia doméstica en Puerto Rico tienen la capacidad y la disposición de ofrecer servicios de albergue y otros servicios a las lesbianas que sean víctimas de violencia? Explique.

\section{Parte 7: Adiestramiento}

67. ¿Cree usted que si las personas que trabajan en agencia de servicios a víctimas de violencia doméstica tuvieran más información sobre la vida de los homosexuales y lesbianas, sobre su realidad social psicológica, tendrían una mejor actitud hacia las personas $\mathrm{GL}$ ?

68. ¿Cree usted que las personas que trabajan en estas organizaciones de servicio o en agencias de gobierno tendrían interés en asistir a un adiestramiento como ese? ¿Por qué sí o por qué no?

69. ¿Podría sugerirnos temas que usted piensa pueden incluirse en ese adiestramiento?

Hemos terminado la entrevista. Muchas gracias por su tiempo y por contestar las preguntas con tanta honestidad. Ahora, si desea hacerme alguna pregunta sobre el estudio o sobre algún asunto relacionado, yo estoy en la mejor 